\title{
Современные исследования эмоционального интеллекта в отечественной психологии
}

\author{
Виктория А. Аитвиненко*, Юлия В. Обухова \\ Южный фредеральный университет, г. Ростов-на-Аону, Россия \\ * E-mail: victoria.cosyachenko@yandex.ru
}

\begin{abstract}
Аннотация
Авторами обосновывается актуальность изучения эмоционального интел^екта, приводятся показатели популярности и востребованности изучения эмоционального интемекта в мире и в России по запросам из базы SciVal. Проведен обзор отечественных научных публикаций по проблематике эмоционального интемлекта на примере анализа 24-х научных статей (3 - инфрормационно-аналитических, 16-эмпирических и 5-методических) из 14-ти журналов, вкАюченных в перечень рецензируемых изАаний, рекоменАованных ВАК (по 19.00.00-Психологические науки, с 2015 по 2020 г.). Анализ публикаций осуществлялся по слеАующим разделам: жанр публикаций, эмпирический объект исслеАования, исслеАовательские методы и методики, области и темы исслеАования.

В результате было установлено, что эмоциональный интемлект изучается вместе с Аругими феноменами, такими как: психические состояния, инАивидные и личностные особенности, профрессиональное выгорание, стратегии совлаАающего повеАения, уАовлетворенность и эорорективность в разных сорерах жизнедеятельности. Наибольшее внимание исслеАователей уделя^ось изучению взаимосвязи эмоционамьного интемлекта с мичностными особенностями. Объектом эмпирических исслеАований преимущественно являлись производственные и образовательные малые группы, а сбор эмпирических Аанных провоАился с помощью разных психологических метоАов (психологическое тестирование, констатирующий эксперимент, полуструктурированное интервью, контент-анализ ответов, аппаратурные методы) и методик, среди которых наиболее часто применялись тесты-опросники.

В заключение Аелается вывоА о том, что уровень эмоционального интемлекта определяет успешность в учебной и трудовой Аеятельности, а также влияет на эфофективность социального взаимодействия. Обозначены прикладные аспекты изучения эмоционального интемекта. Приведены перспективы Аальнейшего собственного эмпирического исследования, отражающего влияние эмоционального интемекта на стратегии учебно-профрессиональной карьеры студентов вуза.
\end{abstract}




\title{
КАючевые слова
}

эмоциональный интемлект, образовательные группы, профрессиональные группы, методы изучения, методики, современные исследования, отечественная психология, обзор исслеАований, статьи, ВАК

Аля цитирования: Аитвиненко В. А., Обухова Ю. В. Современные исследования эмоционального интемлекта в отечественной психологии // Северо-Кавказский психологический вестник. 2020. №18/2. С. 28-43. doi: 10.21702/ncpb.2020.2.3

\section{Modern researches of the emotional intelligence in Russian psychology}

\section{Victoria A. Litvinenko*, Yulia V. Obukhova}

Southern Federal University, Rostov-on-Don, Russia

* Corresponding author. E-mail: victoria.cosyachenko@yandex.ru

\begin{abstract}
In this paper the authors substantiate the relevance and applied value of studying emotional intelligence, review and summarize data on prevalence of this kind of research in Russian and international literature as it is reflected in the SciVal database. A review of domestic scientific publications focused on the issue of emotional intelligence was carried out on a sample of 24 articles (3-descriptive and analytical, 16 -empirical, and 5-methodological) from 14 journals included in the list of peerreviewed publications recommended by the Higher Attestation Commission (indexed 19.00.00-Psychological Sciences), published between 2015 and 2020. These publications were analyzed according to the following categories: publication type, empirical object and conceptual focus of research, research methodology and instruments, areas of application.

It was found that emotional intelligence is typically studied in association with other phenomena, such as: mental states, individual and personality traits, professional burnout, coping strategies, satisfaction and efficiency in various spheres of life. The greatest research attention was given to studying the relationships between emotional intelligence and personality traits. Empirical research focused on professional and educational small groups as its main object and employed for data collection various methods and techniques (e.g., psychological testing, ascertaining experiment, semi-structured interview, content analysis, apparatuses), among which psychological questionnaire were most prevalent.

The review concluded that the level of emotional intelligence largely determines success in educational and work-related activities, and also affects the effectiveness
\end{abstract}


ОБЩАЯ ПСИХОЛОГИЯ, ПСИХОЛОГИЯ ЛИЧНОСТИ

of social interactions. The paper describes applied aspects of research on emotional intelligence are indicated and offers prospects for further empirical research (including own-authored) that would reflect the influence of emotional intelligence on the strategies for educational and professional development of university students.

\section{Keywords}

emotional intelligence, educational groups, professional groups, research methods, techniques, modern research, Russian psychology, research review, articles, Higher Attestation Commission

For citation: Litvinenko V. A., Obukhova Y. V. Modern researches of the emotional intelligence in Russian psychology. Severo-Kavkazskii psikhologicheskii vestnik = North-Caucasian Psychological Bulletin, 2020, no. 18/2, pp. 28-43. doi: 10.21702/ ncpb.2020.2.3 (in Russ.).

\section{ВВЕДЕНИЕ}

Понятие эмоционального интеллекта заработало высокий ранг популярности среди исследователей и практиков в самых разных областях знания. Это подтверждается результатами запросов из научной базы SciVal (таблица 1).

Таблица 1

Показатели популярности и востребованности изучения эмоционального интемлекта в мире и в России (база SciVal)

\begin{tabular}{|c|c|c|c|c|c|}
\hline $\begin{array}{l}\text { SciVal } \\
\text { Topic Clusters } \\
\text { (World) } \\
\text { Emotional } \\
\text { intelligence, } \\
\text { Emotion, Trait } \\
\text { emotional }\end{array}$ & $\begin{array}{l}\text { SciVal } \\
\text { Topic } \\
\text { (World) } \\
50\end{array}$ & $\begin{array}{l}\text { Scholarly } \\
\text { Output } \\
\text { (World) } \\
1,674\end{array}$ & $\begin{array}{l}\text { Publi- } \\
\text { cation } \\
\text { Share } \\
\text { (World) } \\
1,674\end{array}$ & $\begin{array}{l}\text { Field- } \\
\text { Weighted } \\
\text { Citation } \\
\text { Impact } \\
\text { (World) } \\
0,95\end{array}$ & $\begin{array}{l}\text { Prominence } \\
\text { percentile } \\
\text { (World) } \\
98,129\end{array}$ \\
\hline $\begin{array}{l}\text { SciVal } \\
\text { Topic Clusters } \\
\text { (Russia) } \\
\text { Emotional } \\
\text { Intelligence; } \\
\text { Emotions; Trait } \\
\text { emotional }\end{array}$ & $\begin{array}{l}\text { SciVal } \\
\text { Topic } \\
\text { (Russia) } \\
38\end{array}$ & $\begin{array}{l}\text { Scholarly } \\
\text { Output } \\
\text { (Russia) } \\
38\end{array}$ & $\begin{array}{l}\text { Publi- } \\
\text { cation } \\
\text { Share } \\
\text { (Russia) } \\
1,344\end{array}$ & $\begin{array}{l}\text { Field- } \\
\text { Weighted } \\
\text { Citation } \\
\text { Impact } \\
\text { (Russia) } \\
0,24\end{array}$ & $\begin{array}{l}\text { Prominence } \\
\text { percentile } \\
\text { (Russia) } \\
98,129\end{array}$ \\
\hline
\end{tabular}


В зарубежных исследованиях есть подтверждение тому, что уровень эмоционального интеллекта определяет успешность в учебной $[1,2,3]$ и трудовой деятельности [4], а также влияет на эффективность социального взаимодействия [5, 6].

Именно поэтому проблема эмоционального интеллекта актуальна в отечественной и зарубежной психологии. Доказательством этого служит тот факт, что за последние годы были написаны десятки научных статей по проблематике эмоционального интеллекта, разработаны и апробированы методики для измерения эмоционального интеллекта и программы развития эмоционального интеллекта личности на разных этапах онтогенеза.

\section{TЕОРЕТИЧЕСКОЕ ОБОСНОВАНИЕ}

Важным направлением изучения эмоционального интеллекта является аналитический обзор накопленных за рубежом и в нашей стране исследовательских данных за определенный период времени.

Цель исследования: провести обзор отечественной научной литературы, опубликованной в период с 2015 по 2020 г. и посвященной исследованию эмоционального интеллекта.

Объект исследования: научные статьи в отечественных журналах, включенных в перечень ВАК за последние 5 лет; предмет исследования-современные исследования изучения эмоционального интеллекта.

Были отобраны 24 статьи из 14-ти журналов, включенных в перечень рецензируемых изданий, рекомендованных ВАК (таблица 2).

Таблица 2

Количество научных публикаций по проблеме изучения эмоционального интемлекта в журналах, рекоменАованных ВАК

\begin{tabular}{|l|c|c|}
\hline \multicolumn{1}{|c|}{ Название журнала } & $\begin{array}{c}\text { Количество } \\
\text { статей }\end{array}$ & IF \\
\hline $\begin{array}{l}\text { Психология. Журнал Высшей } \\
\text { школы экономики }\end{array}$ & 4 & 2,331 \\
\hline $\begin{array}{l}\text { Вестник Костромского } \\
\text { государственного университета } \\
\text { им. Н. А. Некрасова }\end{array}$ & 4 & 0,299 \\
\hline $\begin{array}{l}\text { Психология и психотехника } \\
\text { Психологические исследования }\end{array}$ & 2 & 0,134 \\
\hline
\end{tabular}


ОБЩАЯ ПСИХОЛОГИЯ, ПСИХОЛОГИЯ ЛИЧНОСТИ

\begin{tabular}{|c|c|c|}
\hline Название журна^а & $\begin{array}{c}\text { Количество } \\
\text { статей }\end{array}$ & IF \\
\hline $\begin{array}{l}\text { Современная зарубежная } \\
\text { психология }\end{array}$ & 2 & 2,013 \\
\hline $\begin{array}{l}\text { Азимут научных исслеАований: } \\
\text { пеАагогика и психо^огия }\end{array}$ & 1 & 0,227 \\
\hline $\begin{array}{l}\text { Социальная психология } \\
\text { и общество }\end{array}$ & 1 & 0,643 \\
\hline $\begin{array}{l}\text { Психолого-педагогические } \\
\text { исследования }\end{array}$ & 1 & 0,674 \\
\hline Психологический журнал & 1 & 1,204 \\
\hline $\begin{array}{l}\text { Российский психологический } \\
\text { журнал }\end{array}$ & 1 & 0,869 \\
\hline $\begin{array}{l}\text { Вестник МПГУ. Серия «Педагогика } \\
\text { и психология» }\end{array}$ & 1 & 0,227 \\
\hline Psychology in Russia: State of the Art & 1 & 1,138 \\
\hline $\begin{array}{l}\text { Национа^ьный психологический } \\
\text { журна^ }\end{array}$ & 1 & 1,513 \\
\hline Вестник Мининского университета & 1 & 0,941 \\
\hline
\end{tabular}

Мы проследили динамику публикационной активности по годам, начиная с 2015 г. Количество опубликованных статей по годам представлено в таблице 3.

Таблица 3

Количество научных публикаций по проблеме изучения эмоционального

\begin{tabular}{|c|c|c|c|c|c|c|}
\hline & интелмекта по голам \\
\hline ГОА & 2015 & 2016 & 2017 & 2018 & 2019 & 2020 \\
\hline КОА-ВО & 4 & 5 & 4 & 4 & 4 & 3 \\
\hline
\end{tabular}


Данная таблица демонстрирует, что интерес исследователей к проблеме эмоционального интеллекта на протяжении рассматриваемого периода практически не менялся.

\section{РЕЗУЛЬТАТЫ}

\section{Жанр (тun) публикаций}

Из 24-х отобранных для анализа статей: в 16-ти представлены результаты эмпирического исследования эмоционального интеллекта, в 3-х проведен информационно-аналитический обзор литературных источников, и в 5-ти описан методический инструментарий для изучения эмоционального интеллекта.

Публикации эмпирической направленности охватывают множество аспектов изучения эмоционального интеллекта, например гендерные различия в эмоциональном интеллекте, связи эмоционального интеллекта с рядом других феноменов (эмоциональной устойчивостью, настроением, профессиональным выгоранием, удовлетворенностью браком и др.).

Меньшее количество исследований информационно-аналитической направленности. Ю. А. Кочетова и М. В. Климакова в своей статье провели обзор методик диагностики эмоционального интеллекта [7]. Еще одна статья данных авторов была посвящена обзору зарубежных исследований агрессии, а также ее связи с эмоциональным интеллектом и его компонентами. Ю. А. Кочетовой и М. В. Климаковой были рассмотрены исследования, результаты которых подтверждали роль эмоционального интеллекта в снижении уровня агрессивности поведения. Эмоциональный интеллект также был рассмотрен как предиктор агрессивного поведения [8]. Е. А. Сергиенко, Е. А. Хлевная и Т. С. Киселева в своей статье провели анализ отечественных и зарубежных исследований, посвященных обсуждению роли эмоционального интеллекта в эффективности деятельности и психологическом благополучии человека [9].

Таким образом, отобранные нами для обзора информационно-аналитические публикации посвящены анализу отечественных и зарубежных исследований, в которых изучается взаимосвязь эмоционального интеллекта с другими феноменами, например психологическим благополучием.

Мы также выделили 5 статей методологической направленности. В двух из них описаны результаты разработки и стандартизации русскоязычной методики ТЭИ («Тест эмоционального интеллекта»), позволяющей измерить уровень развития эмоционального интеллекта. Были доказаны надежность и валидность данного инструментария $[10,11]$. В двух других публикациях представлены методы и методики развития эмоционального интеллекта: а) в статье Т. Д. Савенковой и 3. В. Пархимович описаны концептуальные основания, и предложены методические решения, направленные на развитие эмоционального интеллекта и социальной компетентности детей старшего 
ОБЩАЯ ПСИХОЛОГИЯ, ПСИХОЛОГИЯ ЛИЧНОСТИ

дошкольного возраста в игровой и изобразительной деятельности [12]; б) в статье Н. А. Рыбаковой описываются методические приемы по созданию и использованию эмоционально-ассоциативной интерпретации музыки как средства совершенствования эмоционального интеллекта и повышения эмпатии личности [13]. В статье М. А. Алферовой спроектирована модель каузального исследования зависимости выбора игрового (манипулятивного) или конструктивного паттерна поведения от уровня эмоционального интеллекта, что означает открытие нового источника интерпретационного потенциала транзактного анализа. Результатом исследования является проект однофазного квазиэкспериментального плана с медиатором, который позволяет выявить наличие/отсутствие зависимости выбора манипулятивного/конструктивного паттерна поведения от уровня эмоционального интеллекта [14].

Рассмотрев жанры анализируемых статей, можно сделать вывод, что эмпирические и методологические исследования составляют 87,5 \% от общего числа публикаций. Такие данные указывают на то, что проблема эмоционального интеллекта актуальна для исследователей, которые активно занимаются приращением нового знания и разработкой новых методических приемов.

\section{Tuпы групп в эмпирическом исследовании}

В эмпирических исследованиях объектом изучения выступали различные типы групп. Типы исследуемых групп наглядно продемонстрированы в таблице 4.

Таблица 4

Типы исследуемых групп

\begin{tabular}{|l|c|}
\hline \multicolumn{1}{|c|}{ Типы групп } & Количество статей \\
\hline $\begin{array}{l}\text { Образовательные (Аошкольные, школьные, } \\
\text { студенческие) группы и выпускники различных } \\
\text { специальностей }\end{array}$ & 11 \\
\hline Профессиональные группы: & 6 \\
\hline $\begin{array}{l}\text { Сотрудники контактного центра } \\
\text { телекоммуникационной компании }\end{array}$ & 1 \\
\hline Менеджеры по продажам & 1 \\
\hline Предприниматели & 1 \\
\hline Руководитеми & 2 \\
\hline
\end{tabular}




\begin{tabular}{|l|c|}
\hline \multicolumn{1}{|c|}{ Типы групп } & Количество статей \\
\hline Представители различных профессий & 1 \\
\hline Семейные и летско-родительские отношения & 2 \\
\hline $\begin{array}{l}\text { Иные группы: } \\
\text { Подростки, посещающие центр психолого-меАико- } \\
\text { социального сопровождения }\end{array}$ & 3 \\
\hline Представители субкультуры «хипстеры» & 1 \\
\hline Пользователи социальной сети «ВКонтакте» & 1 \\
\hline
\end{tabular}

Чаще были задействованы образовательные группы: школьные [15, 16], студенческие [17, 18, 19, 20, 21, 22, 23, 24, 25], выпускники различных специальностей [13] и профессиональные группы [19, 21, 26, 27, 28].

В одной из работ изучалось соотношение показателей эмоционального интеллекта и удовлетворенности браком у супругов [29], в другой работе связь эмоционального интеллекта родителей с типом детско-родительских взаимоотношений [30]. Схожие результаты были получены и в статье E. Argyriou, G. Bakoyannis, \& S. Tantaros [25].

Из-за невозможности объединить некоторые группы по типу мы включили их в раздел иных групп. Так, например, в статье Д. П. Ткаченко приведена динамика развития эмоционального интеллекта в процессе социализации подростков в стабильные и кризисные периоды развития общества [24], в статье Е. И. Изотовой и Е. В. Максимовой изучались особенности эмоционального интеллекта подростков - представителей субкультуры «хипстеров» [15], а в статье Ю. А. Кочетовой и М. В. Климаковой исследовалась группа подростков, которые посещают центр психолого-медико-социального сопровождения [16].

\section{Методы изучения эмоционального интеллекта в эмпирическом исследовании}

В 16-ти эмпирических исследованиях, отобранных для дальнейшего анализа, применялись разнообразные методы (см. таблицу 5). 
ОБЩАЯ ПСИхОЛОГИЯ, ПСИхОЛОГИЯ ЛИЧнОСТИ

Таблица 5

Методы изучения эмоционального интемлекта в эмпирических исслеАованиях

\begin{tabular}{|l|c|}
\hline \multicolumn{1}{|c|}{ Наименование метола } & Количество статей \\
\hline Констатирующий эксперимент & 1 \\
\hline Полуструктурированное интервью & 1 \\
\hline Контент-анализ ответов & 1 \\
\hline Тесты-опросники & 16 \\
\hline Аппаратурные метолы & 1 \\
\hline
\end{tabular}

Можно сделать вывод, что во всех публикациях для изучения эмоционального интеллекта применялись тесты-опросники. Чаще всего применялась методика Д. В. Люсина «ЭмИн». Реже применялись такие методики, как MSCEIT v.2.0, тест эмоционального интеллекта Н. Холла, методика исследования эмоционального интеллекта (EQ) в модификации Т. Д. Марцинковской, видеотест Д. В. Люсина и В. В. Овсянниковой.

В некоторых работах применялись сразу несколько из представленных методик. Так, Ю. А. Кочетова и М. В. Климакова в своей статье, наряду с тестами-опросниками, использовали метод констатирующего эксперимента [16].

В исследовании О. А. Ковалёвой для изучения выраженности эмоционального интеллекта использовались тесты-опросники, полуструктурированное интервью и контент-анализ ответов [28].

Кроме этого, в статье Е. И. Изотовой, Е. Б. Максимовой при изучении эмоционального интеллекта при помощи тестов-опросников дополнительно применялся аппаратурный метод. Было установлено, что «использование метода аппаратной диагностики позволяет констатировать изменения функционального состояния испытуемого, а также выделить эмоционально значимые для него опросные зоны» [15, с. 7].

\section{Области и темы исследования}

Мы также проанализировали публикации по областям и темам исследования эмоционального интеллекта. Чаще всего внимание авторов фокусировалось на изучении связи и взаимосвязи эмоционального интеллекта с другими феноменами: 
- с динамическими характеристиками настроения и настроением в целом $[20,21]$;

- с синдромом профессионального выгорания [26];

- со скоростью переработки эмоционально окрашенной информации [13];

- со способностью к принятию агрессии [27];

- со стратегиями совладающего поведения [28];

- с темпераментными свойствами [17];

- с личностными особенностями [22];

- со степенью удовлетворенности браком [29];

- с типом детско-родительских отношений [30].

В некоторых работах авторы изучали роль эмоционального интеллекта, рассматривая его: как фактор в процессе социализации и становления субъектности в подростковом возрасте [24]; «как предиктор стратегий многоэтапных решений в ситуации неопределенности, моделируемой в игровой задаче Айова» [19, с. 39].

Также в двух исследованиях изучались особенности эмоционального интеллекта: студентов HR-менеджеров [18]; подростков и юношей - представителей различных социальных групп [15].

Кроме того, в двух работах внимание авторов было сфокусировано на сравнении различных характеристик эмоционального интеллекта: межкультурном сравнении [25]; сравнении гендерных различий в структуре эмоционального интеллекта [16].

\section{ЗАКЛЮЧЕНИЕ}

Таким образом, проведенный обзор отечественных научных публикаций по проблематике эмоционального интеллекта позволил нам понять:

- какой тип публикаций и в какой мере проводился по данной проблематике с 2015 по 2020 г. в рецензируемых научных изданиях, рекомендованных ВАК по 19.00.00 - Психологические науки;

- на каких группах больше проводилось исследований;

- какие прикладные аспекты изучения эмоционального интеллекта вызывают наибольший интерес у исследователей;

- какие методы и методики чаще всего использовались для изучения эмоционального интеллекта.

В целом данный обзор позволил выявить актуальные проблемы и тенденции в изучении эмоционального интеллекта. Перспективу дальнейшего изучения мы видим в проведении собственного эмпирического исследования, отражающего влияние эмоционального интеллекта на стратегии учебно-профессиональной карьеры студентов вуза. 
ОБЩАЯ ПСИХОЛОГИЯ, ПСИхОЛОГИЯ ЛИЧнОСТИ

\section{ЛИТЕРАТУРА}

1. Barchard K. A. Does emotional intelligence assist in the prediction of academic success? // Educational and Psychological Measurement. 2003. Vol. 63, Issue 5. P. 840-858. DOI: 10.1177/0013164403251333

2. Naeem N., van der Vleuten C., Muijtjens A. M. M., Violato C., Ali S. M., Al-Faris E. A., Hoogenboom R., Naeem N. Correlates of emotional intelligence: Results from a multi-institutional study among undergraduate medical students // Medical Teacher. 2014. Vol. 36, Issue sup1. P. S30-S35.

3. Tekle Z. D., Demeke A., Sado I. A., Damota M. D. The relationship between emotional intelligence and academic achievement among undergraduate students at Madda Walabu University // New Media and Mass Communication. 2019. Vol. 85. P. 10-14. DOI: $10.7176 / \mathrm{NMMC} / 85-02$

4. Nieto-Flores M.-P., Berrios M. P., Extremera N. Job search self-efficacy as a mediator between emotional intelligence and the active job search process // International Journal of Social Psychology. 2019. Vol. 34, Issue 1. P. 86-109. DOI: 10.1080/02134748.2018.1537652

5. Kornilova T. V., Chumakova M. A., Krasavtseva Yu. V. Emotional intelligence, patterns for coping with decisional conflict, and academic achievement in cross-cultural perspective (evidence from selective Russian and Azerbaijani student populations) // Psychology in Russia: State of the Art. 2018. Vol. 11, Issue 2. P. 114-133. DOI: $10.11621 /$ pir.2018.0209

6. Urquijo I., Extremera N., Villa A. Emotional intelligence, life satisfaction, and psychological well-being in graduates: The mediating effect of perceived stress // Applied Research in Quality of Life. 2016. Vol. 11. P. 1241-1252. DOI: 10.1007/s11482-015-9432-9

7. Кочетова Ю. А., Климакова М. В. Методы диагностики эмоционального интеллекта // Современная зарубежная психология. 2019. Т. 8, № 4. C. 106-114. DOI: $10.17759 / j m f p .2019080411$

8. Кочетова Ю. А., Климакова М. В. Эмоциональный интеллект и агрессия в зарубежных исследованиях // Современная зарубежная психология. 2019. T. 8, № 3. C. 29-36. DOI: $10.17759 / j m f p .2019080303$

9. Сергиенко Е. А., Хлевная Е. А., Киселёва Т. С. Роль эмоционального интеллекта в эффективности деятельности и психологическом благополучии человека // Вестник Костромского государственного университета. Серия: Педагогика. Психология. Социокинетика. 2020. Т. 26, № 1. С. 46-53.

10. Сергиенко Е. А., Хлевная Е. А., Ветрова И. И., Киселёва Т. С. Факторная и структурная валидность методики ТЭИ (тест эмоционального интеллекта) // Вестник Костромского государственного университета. Серия: Педагогика. Психология. Социокинетика. 2017. Т. 23, № 3. С. 33-36. 
11. Сергиенко Е. А., Хлевная Е. А., Ветрова И. И., Никитина А. А. Тест эмоционального интеллекта - русскоязычная методика // Социальная психология и общество. 2019. Т. 10, № 3. C. 177-192. DOI: $10.17759 /$ sps.2019100311

12. Пархимович 3. В., Савенкова Т. Д. Методики развития эмоционального интеллекта и социальной компетентности ребенка средствами игровой и художественной деятельности // Вестник МГПУ. Серия: Педагогика и психология. 2018. № 2. С. 107-120.

13. Рыбакова Н. А. Развитие эмоционального интеллекта средствами музыки // Психология и Психотехника. 2015. № 2. С. 150-158. DOI: 10.7256/2070-8955.2015.2.14080

14. Алферова М. А. Эмоциональный интеллект сквозь призму трансактного анализа // Азимут научных исследований: педагогика и психология. 2019. T. 8, № 1. С. 312-316.

15. Изотова Е. И., Максимова Е.Б. Психологические и психофизиологические аспекты исследования эмоционального интеллекта в подростковом и юношеском возрастах // Психологические исследования. 2016. Т. 9, № 46. С. 7.

16. Кочетова Ю. А., Климакова М. В. Гендерные различия в эмоциональном интеллекте у старших подростков // Психолого-педагогические исследования. 2017. T. 9, № 4. С. 65-74. DOI: $10.17759 /$ psyedu.2017090407

17. Баландина Л. Л. Эмоциональный интеллект и его взаимосвязь с темпераментными свойствами // Вестник ПГГПУ. Серия № 1. Психологические и педагогические науки. 2017. № 1. С. 5-14.

18. Гришина А. В., Исаева О. М., Савинова С. Ю. Эмоциональный интеллект студентов - HR-менеджеров // Вестник Мининского университета. 2018. T. 6, № 2. C. 16. DOI: 10.26795/2307-1281-2018-6-2-16

19. Красавчева Ю. В., Корнилова Т. В. Эмоциональный и академический интеллект как предикторы стратегий в игровой задаче Айова (IGT) // Психологический журнал. 2018. Т. 39, № 3. С. 29-43.

20. Lyusin D., Mohammed A. Are emotionally intelligent people more emotionally stable? An experience sampling study // Psychology. Journal of Higher School of Economics. 2020. Vol. 17, № 2. P. 315-327. DOI: $10.17323 / 1813-$ 8918-2020-2-315-327

21. Люсин Д. В., Овсянникова В. В. Связь эмоционального интеллекта и личностных черт с настроением // Психология. Журнал Высшей школы экономики. 2015. Т. 12, № 3. С. 154-164.

22. Собкин В. С., Лыкова Т. А. Взаимосвязь эмоционального интеллекта и личностных особенностей (по материалам обследования студентов театрального колледжа) // Национальный психологический журнал. 2015. № 2. C. 56-65. DOI: 10.11621/npj.2015.0206 
23. Сысоева Т. А., Овсянникова В. В. Скорость переработки эмоциональной информации как коррелят эмоционального интеллекта // Психология. Журнал Высшей школы экономики. 2015. Т. 12, № 2. С. 160-171.

24. Ткаченко Д. П. Изменения эмоционального интеллекта в процессе социализации подростков в стабильные и кризисные периоды развития общества // Психологические исследования. 2018. Т. 11, № 61. С. 7.

25. Argyriou E., Bakoyannis G., Tantaros S. Parenting styles and trait emotional intelligence in adolescence // Scandinavian Journal of Psychology. 2016. Vol. 57, Issue 1. P. 42-49. DOI: $10.1111 /$ sjop. 12266

26. Бочкарева Е. Н. Взаимосвязь профессионального выгорания и эмоционального интеллекта сотрудников контактного центра // Психология. Журнал Высшей школы экономики. 2016. Т. 13, № 3. С. 576-587. DOI: 10.17323/1813-8918-2016-3-576-587

27. Воробьева Е. В., Перков М. А., Щетинина Д. П. Исследование взаимосвязи принятия агрессии и эмоционального интеллекта // Российский психологический журнал. 2017. Т. 14, № 2. С. 28-50. DOI: 10.21702/rpj.2017.2.2

28. Ковалёва О.А. Связь эмоционального интеллекта со стратегиями совладающего поведения предпринимателей и топ-менеджеров // Вестник КГУ им. Н. А. Некрасова. Серия: Педагогика. Психология. Социальная работа. Ювенология. Социокинетика. 2015. Т. 21, № 4. С. 125-129.

29. Шлыкова Н. И., Полянина О. И. Эмоциональный интеллект и удовлетворённость браком: различия, взаимосвязь и особенности структуры данных показателей у мужчин и женщин // Психология и Психотехника. 2016. № 5. C. 415-419. DOI: 10.7256/2070-8955.2016.5.20156

30. Комлик Л. Ю., Меренкова В. С. Взаимосвязь эмоционального интеллекта родителей и детско-родительских отношений // Вестник КГУ. Серия: Педагогика. Психология. Социокинетика. 2017. Т. 23, № 3. С. 37-40.

\section{REFERENCES}

1. Barchard K. A. Does emotional intelligence assist in the prediction of academic success? Educational and Psychological Measurement, 2003, V. 63, Issue 5, pp. 840-858. DOI: 10.1177/0013164403251333

2. Naeem N., van der Vleuten C., Muijtjens A. M. M., Violato C., Ali S. M., AlFaris E. A., Hoogenboom R., Naeem N. Correlates of emotional intelligence: Results from a multi-institutional study among undergraduate medical students. Medical Teacher, 2014, V. 36, Issue sup1, pp. S30-S35.

3. Tekle Z. D., Demeke A., Sado I. A., Damota M. D. The relationship between emotional intelligence and academic achievement among undergraduate students at Madda Walabu University. New Media and Mass Communication, 2019, V. 85, pp. 10-14. DOI: $10.7176 / \mathrm{NMMC} / 85-02$ 
4. Nieto-Flores M.-P., Berrios M. P., Extremera N. Job search self-efficacy as a mediator between emotional intelligence and the active job search process. International Journal of Social Psychology, 2019, V. 34, Issue 1, pp. 86-109. DOI: 10.1080/02134748.2018.1537652

5. Kornilova T. V., Chumakova M. A., Krasavtseva Yu. V. Emotional intelligence, patterns for coping with decisional conflict, and academic achievement in cross-cultural perspective (evidence from selective Russian and Azerbaijani student populations). Psychology in Russia: State of the Art, 2018, V. 11, Issue 2, pp. 114-133. DOI: 10.11621/pir.2018.0209

6. Urquijo I., Extremera N., Villa A. Emotional intelligence, life satisfaction, and psychological well-being in graduates: The mediating effect of perceived stress. Applied Research in Quality of Life, 2016, V. 11, pp. 1241-1252. DOI: 10.1007/s11482-015-9432-9

7. Kochetova Y. A., Klimakova M. V. Methods for diagnosing emotional intelligence. Sovremennaya zarubezhnaya psikhologiya = Journal of Modern Foreign Psychology, 2019, V. 8, no. 4, pp. 106-114. DOI: $10.17759 /$ imfp.2019080411 (in Russ.).

8. Kochetova Y. A., Klimakova M. V. Emotional intelligence and aggression in foreign studies. Sovremennaya zarubezhnaya psikhologiya = Journal of Modern Foreign Psychology, 2019, V. 8, no. 3, pp. 29-36. DOI: $10.17759 /$ jmfp.2019080303 (in Russ.).

9. Sergiyenko Y. A., Khlevnaya Y. A., Kiselyova T. S. The role of emotional intellect in human performance and psychological well-being. Vestnik Kostromskogo gosudarstvennogo universiteta. Seriya:Pedagogika. Psikhologiya. Sotsiokinetika = Vestnik of Kostroma State University. Series: Pedagogy. Psychology. Sociokinetics, 2020, V. 26, no. 1, pp. 46-53. (in Russ.).

10. Sergiyenko Y. A., Khlevnaya Y. A., Vetrova I. I., Kiselyova T. S. Factorial and structural validity of emotional intelligence testing technique. Vestnik Kostromskogo gosudarstvennogo universiteta. Seriya:Pedagogika. Psikhologiya. Sotsiokinetika = Vestnik of Kostroma State University. Series: Pedagogy. Psychology. Sociokinetics, 2017, V. 23, no. 3, pp. 33-36. (in Russ.).

11. Sergienko E. A., Khlevnaya E. A., Vetrova I. I., Nikitina A. A. The test of emotional intelligence - a Russian-speaking method. Sotsial'naya psikhologiya i obshchestvo = Social Psychology and Society, 2019, V. 10, no. 3, pp. 177-192. DOI: $10.17759 /$ sps.201910031 (in Russ.).

12. Parkhimovich Z. V., Savenkova T. D. Methods of development of emotional intelligence and social competence of children by means of play and artistic activities. Vestnik Moskovskogo gorodskogo pedagogicheskogo universiteta. Seriya: Pedagogika i psikhologiya, 2018, no. 2, pp. 107-120. (in Russ.).

13. Rybakova N. A. Developing of emotional intelligence by means of music. 
Psikhologiya i Psikhotekhnika = Psychology and Psychotechnics, 2015, no. 2, pp. 150-158. DOI: 10.7256/2070-8955.2015.2.14080 (in Russ.).

14. Alferova M. A. Emotional intelligence through the prism of transactional analysis. Azimut nauchnykh issledovanii: pedagogika i psikhologiya $=$ Azimuth of Scientific Research: Pedagogy and Psychology, 2019, V. 8, no. 1, pp. 312-316. (in Russ.).

15. Izotova E. I., Maksimova E. B. Psychological and physiological aspects of the study of emotional intelligence in adolescence and adulthood. Psikhologicheskie issledovaniya, 2016, V. 9, no. 46, p. 7. (in Russ.).

16. Kochetova Y. A., Klimakova M. V. Gender differences in emotional intelligence in adolescence. Psikhologo-pedagogicheskie issledovaniya $=$ Psychological-Educational Studies, 2017, V. 9, no. 4, pp. 65-74. DOI: $10.17759 /$ psyedu.2017090407 (in Russ.).

17. Balandina L. L. Emotional intelligence and its corellation with temperament features. Vestnik Permskogo gosudarstvennogo gumanitarno-pedagogicheskogo universiteta. Seriya № 1. Psikhologicheskie i pedagogicheskie nauki, 2017, no. 1, pp. 5-14. (in Russ.).

18. Grishina A. V., Isaeva O. M., Savinova S. Yu. Emotional intelligence of HRmanagement students. Vestnik Mininskogo universiteta $=$ Vestnik of Minin University, 2018, V. 6, no. 2, p. 16. DOI: 10.26795/2307-1281-2018-6-2-16 (in Russ.).

19. Krasavtseva Ju. V., Kornilova T. V. Emotional and academic intelligence as strategy predictors in the lowa Gambling Task (IGT). Psikhologicheskii zhurnal, 2018, V. 39, no. 3, pp. 29-43. (in Russ.).

20. Lyusin D., Mohammed A. Are emotionally intelligent people more emotionally stable? An experience sampling study. Psychology. Journal of Higher School of Economics, 2020, V. 17, no. 2, pp. 315-327. DOI: 10.17323/18138918-2020-2-315-327

21. Lyusin D. V., Ovsyannikova V. V. Relationships between emotional intelligence, personality traits and mood. Psikhologiya. Zhurnal Vysshei shkoly ekonomiki = Psychology. Journal of the Higher School of Economics, 2015, V. 12, no. 3, pp. 154-164. (in Russ.).

22. Sobkin V. S., Lykova T. A. The relationship of emotional intelligence and personality traits (abridged from the survey of students of the Theatre College). Natsional'nyi psikhologicheskii zhurnal = National Psychological Journal, 2015, no. 2, pp. 56-65. DOI: 10.11621/npj.2015.0206 (in Russ.).

23. Sysoeva T. A., Ovsyannikova V.V. Speed of emotional information processing as correlate of emotional intelligence. Psikhologiya. Zhurnal Vysshei shkoly ekonomiki = Psychology. Journal of the Higher School of Economics, 2015, V. 12, no. 2, pp. 160-171. (in Russ.). 
24. Tkachenko D. P. Changes of emotional intelligence in the process of socialization of adolescents in the stable and crisis periods of the development of society. Psikhologicheskie issledovaniya, 2018, V. 11, no. 61, p. 7. (in Russ.).

25. Argyriou E., Bakoyannis G., Tantaros S. Parenting styles and trait emotional intelligence in adolescence. Scandinavian Journal of Psychology, 2016, V. 57, Issue 1, pp. 42-49. DOI: $10.1111 /$ sjop.12266

26. Bochkareva $E$. The interrelation of burnout and emotional intelligence in callcentre workers. Psikhologiya. Zhurnal Vysshei shkoly ekonomiki=Psychology. Journal of the Higher School of Economics, 2016, V. 13, no. 3, pp. 576-587. DOI: 10.17323/1813-8918-2016-3-576-587 (in Russ.).

27. Vorobyeva E. V., Perkov M. A., Shchetinina D. P. Studying the association between acceptance of aggression and emotional intelligence. Russian Psychological Journal, 2017, V. 14, no. 2, pp. 28-50. DOI: $10.21702 /$ rpj.2017.2.2 (in Russ.).

28. Kovalyova O. A. Correlations between emotional intelligence and copingstrategies in businessmen and top managers. Vestnik KGU im. N. A. Nekrasova. Seriya: Pedagogika. Psikhologiya. Sotsial'naya rabota. Yuvenologiya. Sotsiokinetika, 2015, V. 21, no. 4, pp. 125-129. (in Russ.).

29. Shlykova N. I., Polyanina O. I. Emotional intelligence and satisfaction with marriage: The differences, the relationship and the particular structure of these indicators for both men and women. Psikhologiya i Psikhotekhnika $=$ Psychology and Psychotechnics, 2016, no. 5, pp. 415-419. DOI: 10.7256/20708955.2016.5.20156 (in Russ.).

30. Komlik L. Y., Merenkova V. S. The relationship of emotional intelligence of parents and parent-child relationship. Vestnik KGU. Seriya: Pedagogika. Psikhologiya. Sotsiokinetika, 2017, V. 23, no. 3, pp. 37-40. (in Russ.). 